\title{
Cenários da Educação de mulheres jovens e adultas em situação de privação de liberdade no contexto brasileiro*
}

\author{
Maria Celeste Reis Fernandes de Souza ${ }^{a}$ \\ Eunice Maria Nazareth Nonato ${ }^{b}$ \\ Maria da Conceição Ferreira Reis Fonseca ${ }^{c}$
}

\section{Resumo}

Neste artigo, discutimos a oferta de Educação escolar para mulheres aprisionadas, buscando identificar, nessa oferta, reflexos das singularidades da condição feminina e desigualdades de gênero historicamente constituídas. O corpus documental analisado é composto por Planos Estaduais de Educação nas Prisões dos 26 estados da Federação, disponíveis no sítio eletrônico do Departamento Penitenciário do Ministério da Justiça e Segurança Pública. A análise dos dados, trazidos por tais planos, dialoga com reflexões e empiria de outros estudos sobre Educação e gênero no sistema prisional do Brasil. Os resultados indicam avanços no campo legal, mas apontam um longo caminho a percorrer para a garantia do direito à Educação escolar na prisão, em especial, para as mulheres: nos diferentes locais e tipos de aprisionamento, é preciso desenvolver processos educativos que as tornem visíveis e que considerem as tramas nas quais as desigualdades de gênero se entrelaçam.

Palavras-chave: Gênero. Educação. Sistema prisional.

\section{Introdução}

Os cenários da Educação de mulheres em situação de privação de liberdade no Brasil inscrevem-se no reconhecimento do direito à Educação das

\footnotetext{
* Financiamento: Conselho Nacional de Desenvolvimento Científico e Tecnológico.

a Universidade Vale do Rio Doce, Governador Valadares, MG, Brasil.

b Universidade Vale do Rio Doce, Governador Valadares, MG, Brasil.

c Universidade Federal de Minas Gerais, Belo Horizonte, MG, Brasil.
} 
pessoas jovens e adultas que se encontram nessa condição, e é urdido na força de movimentos sociais, no aprofundamento das reflexões teóricas e na construção de um arcabouço legal no campo da Educação, dos direitos humanos e dos estudos de gênero que denunciam as persistentes desigualdades entre mulheres e homens (CORCETTI; SOUZA; LORETO, 2018; MEYER et al., 2014).

Na perspectiva ocidental, a Declaração Universal dos Direitos Humanos (ONU, 1948) estabelece um marco de luta contra processos de opressão e de discriminação, ao promulgar a igualdade e a dignidade das pessoas, reconhecendo os direitos e as liberdades fundamentais como inerentes às relações igualitárias e à garantia de uma vivência digna. $\mathrm{O}$ artigo $1^{\circ}$ desse documento afirma que "todos os seres humanos nascem livres e iguais em dignidade e direitos" (ONU, 1948), e o Artigo $2^{\circ}$ delimita que não deve haver "[...] distinção de qualquer espécie, seja de raça, cor, sexo, língua, religião, opinião política ou de outra natureza, origem nacional ou social, riqueza, nascimento, ou qualquer outra condição" (ONU, 1948). Assim, tem-se, a partir dessa declaração, a manifestação expressa de que a igualdade de direitos se encontra ancorada na própria dignidade humana, desvinculada de qualquer outra condicionalidade no âmbito político ou civil. Por sua vez, a Educação comparece como direito social, no artigo $6^{\circ}$ da Constituição Federal (BRASIL, 1988) e, enquanto direito social, remete ao Estado a responsabilidade de sua garantia a todos.

No cenário da garantia do direito à Educação, é importante destacar que a Lei de Execução Penal Brasileira (LEP) (BRASIL, 1984) assegura a assistência educacional a pessoas em situação de aprisionamento, o que é ratificado em alterações posteriores, definindo responsabilidades pela oferta e financiamento da Educação escolar, ou ampliando as possibilidades da oferta de Educação nas prisões.

Outro marco legal da garantia do direito à Educação nas prisões é a Constituição Federal de 1988, que reafirma como princípio a "igualdade de condições para o acesso e permanência na escola" (BRASIL, 1988). Assumindo os princípios da Constituição Federal, a Lei de Diretrizes e Bases da Educação Nacional asseguraria, à população jovem e adulta, o direito à Educação regular "com características e modalidades adequadas às suas necessidades e disponibilidades" (BRASIL, 1996). 
Julião (2013), ao traçar um panorama histórico sobre a Educação no contexto prisional brasileiro, afirma que, embora possam ser registradas experiências em diferentes estados há algumas décadas, é a partir de 2005

[...] que se inicia no Brasil encaminhamentos para implementação de uma política propriamente nacional, quando os Ministérios da Educação e da Justiça iniciaram uma proposta de articulação para implementação de Programa Nacional de Educação no Sistema Penitenciário, formulando as suas diretrizes (p. 15).

Como resultado dessa articulação, instauram-se no país debates sobre a Educação Prisional, que culminaram na realização de seminários nacionais nos anos de 2006, 2007 e 2012 (JULIÃO, 2013), e intensificaram, tanto a elaboração de propostas educativas, como a reflexão acadêmica sobre o tema (IRELAND, 2011; JULIÃO, 2013; ONOFRE; JULIÃO, 2013).

Abre-se, desse modo, a possibilidade de avanços na garantia do direito à Educação nas prisões, respaldados por um conjunto de marcos legais, que definem responsabilidades e estratégias com vistas a viabilizar a oferta educativa naqueles espaços. Contribuem para tais avanços as Diretrizes Nacionais para a Oferta de Educação para Jovens e Adultos em Situação de Privação de Liberdade nos Estabelecimentos Penais (BRASIL, 2010), o Plano Estratégico de Educação no âmbito do Sistema Prisional (Peesp) (BRASIL, 2011a), a modificação legislativa realizada pela Lei $\mathrm{n}^{\circ}$ 12.433/2011, que altera a LEP, incluindo a Educação como fator de remição de parte do tempo da sentença condenatória de prisão ${ }^{1}$.

Todavia, a inclusão da pessoa jovem e adulta no sistema de Educação formal, levando-se em conta, não apenas, as peculiaridades do contexto do encarceramento e as especificidades de cada medida ou regime prisional, mas também, as particularidades das condições sociais, culturais, de gênero, de raça, de etnia, de credo e de idade, embora assegurados no texto das diretrizes e demais legislações aventadas, coloca-se ainda como um desafio (JULIÃO, 2013, 2016). Nesse sentido, as preocupações com a Educação de mulheres presas, objeto de discussão deste artigo, encontram-se correlacionadas não só com o aumento das mulheres nas prisões brasileiras, mas também com as desigualdades de gênero historicamente constituídas que impactam seu acesso ao direito à Educação.

A lei prevê um dia de redução de pena a cada 12 horas de frequência escolar, divididas, no mínimo, em três dias (BRASIL, 2011b). 
Ao final da primeira década deste milênio, em relatório elaborado sobre a Educação nas prisões brasileiras, Carreira (2009) apontava para o aumento do público feminino no sistema prisional desde 2002: "a taxa de crescimento das mulheres nas prisões brasileiras é cerca de 2,5 vezes a dos homens" (p. 21). Esse aumento vem sendo identificado ao longo dos anos nos levantamentos nacionais, como se apresenta, por exemplo, no Levantamento Nacional de Informações Penitenciárias (Infopen), publicado no ano de 2014:

em que pese a expressiva participação de homens no contingente total de pessoas privadas de liberdade no país, é possível afirmar que a população absoluta de mulheres encarceradas no sistema penitenciário cresceu 567\% entre os anos de 2000 a 2014, chegando ao patamar de 37.380 mulheres (BRASIL, 2014, p. 10).

O Infopen, publicado em 2018, confirma o aumento da população prisional feminina que, em junho de 2016, "atingiu a marca de 42 mil mulheres privadas de liberdade, o que representa um aumento de $656 \%$ em relação ao total registrado no início dos anos 2000, quando menos de 6 mil mulheres se encontravam no sistema prisional"(BRASIL, 2018, p. 14)2.

Neste artigo, procuramos traçar um cenário da Educação de mulheres jovens e adultas em situação de aprisionamento no Brasil e discutir a oferta de Educação escolar para essas mulheres por meio da análise dos Planos Estaduais de Educação nas Prisões de 26 estados da federação. Nessa discussão, tomamos, ainda, como referência as contribuições de documentos legais que se debruçam sobre a condição e a situação feminina nesse espaço, e nos baseamos em dados secundários, extraídos de outros estudos sobre gênero e sobre o sistema prisional, buscando evidenciar as tramas nas quais as singularidades e as desigualdades de gênero se entrelaçam no espaço da prisão e adentram as salas de aula.

\section{Cenários}

O Peesp (BRASIL, 2011a) apresenta como objetivos: universalizar a alfabetização; ampliar a oferta de Educação no sistema prisional; fortalecer a integração da Educação profissional e tecnológica com a Educação de Jovens e Adultos (EJA); viabilizar a continuidade de estudos dos egressos do sistema prisional; investir na formação de profissionais envolvidos na implementação do ensino nos

${ }^{2}$ O Brasil tem a quarta maior população de mulheres encarceradas no mundo e figura na terceira posição com relação a taxa de aprisionamento "que indica o número de mulheres presas para cada grupo de 100 mil mulheres" (BRASIL, 2018, p. 13). 
estabelecimentos penais. Para garantir o êxito desses objetivos, o Plano confere prioridade à execução de ações conjuntas e troca de informações entre órgãos federais, estaduais e do Distrito Federal com atribuições nas áreas de Educação e de execução penal, e incentiva "a elaboração de planos estaduais de Educação para o sistema prisional, abrangendo metas e estratégias de formação educacional da população carcerária e dos profissionais envolvidos em sua implementação" (BRASIL, 2011a). Nesse sentido, o Peesp contribui para resolver alguns imbróglios da Educação nas prisões decorrentes do fato de o Sistema Prisional estar vinculado ao Ministério da Justiça, enquanto as escolas reportam-se ao Ministério da Educação.

Tomamos como objeto de discussão, nesta seção, 26 Planos Estaduais de Educação nas Prisões, elaborados pelas Unidades Federativas ${ }^{3}$ (UF), que se encontram disponíveis no sítio eletrônico do Departamento Penitenciário do Ministério da Justiça e Segurança Pública (http://depen.gov.br/DEPEN), elaborados no período de 2012 a 2015, e acessados, para este estudo, em janeiro de $2018^{4}$. Embora a leitura desses planos permita identificar a demanda e a possibilidade de oferta de diferentes níveis e modalidades de Educação nas prisões, neste artigo focalizamos a demanda e o atendimento da EJA para a população carcerária e, especificamente, para mulheres, considerando que o direito à Educação Básica é garantido pela Constituição Brasileira, inclusive para pessoas adultas que a ela não tiveram acesso. Nesta reflexão sobre possibilidades e limites da garantia do direito à Educação, para homens e mulheres, endereçamos nosso olhar para as especificidades e singularidades de gênero demarcadas pelas persistentes desigualdades de gênero que ecoam nas práticas educativas, e são nelas, e por elas, fortalecidas (LOURO, 1997; PARAÍSO; CALDEIRA, 2018). Essas desigualdades ecoam também no contexto da Educação nas prisões, posto que tais desigualdades atravessam os muros da prisão e se instalam, talvez ainda mais fortemente, em seu interior.

Em nosso exercício analítico, orientamo-nos pela proposição feita por Scott (1990), que concebe duas dimensões do conceito de gênero: uma primeira dimensão, ligada à compreensão de que as diferenças de gênero são produzidas nas relações sociais, entre mulheres e homens, sendo o gênero constitutivo dessas relações e constituído nelas; e uma outra dimensão que remete à compreensão de que essas relações são atravessadas por relações de poder multifacetárias e pulverizadas, que não se concentram "no homem" ou "na mulher", mas se disseminam em

3 O Brasil encontra-se dividido em 26 UF e o Distrito Federal. O Plano do Distrito Federal não se encontrava disponível.

${ }^{4}$ Foi realizado novo acesso em setembro de 2019 e os documentos continuavam indisponíveis. Não se registra no sítio eletrônico atualização dos Planos. 
todo o corpo social, sendo o gênero um primeiro modo de significá-las, "um primeiro campo no seio do qual, ou por meio do qual, o poder é articulado" (SCOTT, 1990, p. 16).

Desse modo, ao tratar da Educação de mulheres presas, compreendemos que o gênero encontra-se ligado às relações entre mulheres e homens, mas também a outros tantos sistemas simbólicos e institucionais, a normas legais e a sanções, aos modos de organização da prisão e da escola, a hierarquias, regulamentos, comportamentos e aos modos discursivamente construídos de "ser homem" e de "ser mulher", que demarcam diferenças e desigualdades de gênero.

\subsection{Demanda e atendimento da EJA}

A questão da garantia de efetivação do que se encontra posto no campo legal sobre o direito à Educação na prisão tem sido objeto de preocupações de diferentes estudos no Brasil, que o reafirmam como direito humano e social, potencializador do processo de ressocialização, ao mesmo tempo em que enfatizam a necessidade de tornar efetivas as ações nesse contexto, especialmente na equalização entre a demanda e o atendimento (IRELAND, 2011; JULIÃO, 2016; ONOFRE; JULIÃO, 2013).

No Brasil, a etapa da discussão do direito desse público à Educação já foi, segundo Onofre e Julião (2013), ultrapassada. Para esses autores, o país encontra-se agora em um segundo estágio, no qual, deve analisar as práticas e as experiências empreendidas nesse campo, procurando avaliá-las para instituir programas e consolidar propostas e políticas. O estudo dos Planos Estaduais que procedemos permite traçar um panorama do amplo conjunto da demanda por Educação, do atendimento e da efetividade do que está posto no campo legal para oferta da escola na prisão.

Considerando-se a oferta de Educação formal nos estabelecimentos prisionais - Alfabetização, Ensino Fundamental (EF) e Ensino Médio (EM) - temos, no cenário nacional, uma desigualdade assustadora entre a demanda (entendida como o número dos que não concluíram aquele nível da Educação Básica) e o atendimento por nível de escolaridade, conforme os dados extraídos dos Planos analisados, e que consolidamos ${ }^{5}$ por região brasileira, como se pode conferir na Tabela 1.

Dados organizados por região conforme informações de cada Plano: em 2012 foram elaborados seis Planos; 2014, um Plano; 2015, 19 Planos. Embora todos os documentos não sejam do mesmo ano, considerou-se que esse lapso temporal não compromete o panorama traçado entre a demanda e oferta de EJA. 


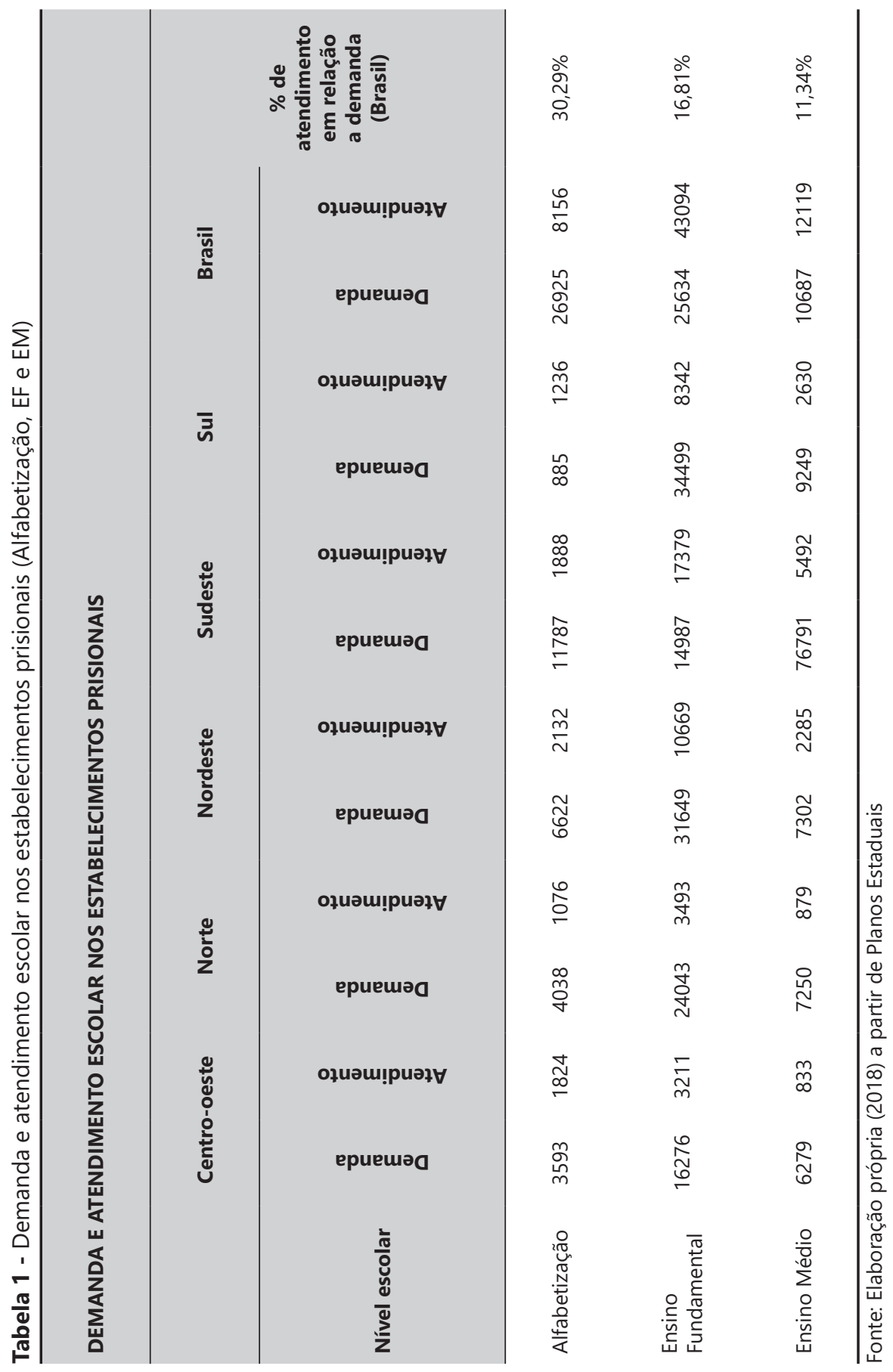


Os dados apresentados na Tabela 1 evidenciam que o direito à Educação, que não foi garantido a essas pessoas na infância, adolescência ou juventude, continua a lhes ser negado no contexto do encarceramento. Em todas as regiões brasileiras ocorre um descompasso entre a demanda por escolarização das pessoas em situação de aprisionamento e a oferta de Educação escolar nas prisões: na alfabetização, o atendimento cobre apenas 30,29\% da demanda; no EF, 16,81\%; e, no EM, 11,34\%. No total, a defasagem entre a necessidade de escola e a sua oferta é de $83,76 \%$.

Aos dados extraídos dos Planos Estaduais, devem-se acrescentar as informações do Levantamento Nacional De Informações Penitenciárias (MOURA, 2019) relativas à escolaridade das pessoas privadas de liberdade: 51,3\% têm o EF incompleto; $13,1 \%$ concluíram o EF; e 14,9\% completaram o EM. Segundo o documento "no sistema penitenciário, mais da metade das pessoas custodiadas possuem baixa escolaridade, ao passo que, entre a população brasileira, percebese maior dispersão entre todos os níveis educacionais" (MOURA, 2019, p. 35).

Assim, a privação de liberdade define outras tantas privações, dentre as quais, o acesso à escola daqueles (as) que não foram atingidos (as) pela universalização do $\mathrm{EF}$ antes do aprisionamento e continuam à margem da garantia do direito humano e social à Educação Básica. Embora a elaboração dos Planos Estaduais seja um indicativo das intenções da garantia desse direito, os dados neles apresentados e as projeções de ampliação de vagas, sempre reduzidas com relação à demanda, nos fazem suspeitar da efetividade das ações propostas.

Nesses planos, diferentes necessidades são apresentadas para a oferta do ensino formal nas prisões: ampliação das salas de aula, melhoria de espaços e equipamentos, formação de professores, gestores e agentes penitenciários. Com relação a esses últimos, os planos reiteram o número insuficiente desses profissionais que, dentre outras funções, devem acompanhar os (as) estudantes em seus deslocamentos intramuros (alojamento-escola-alojamento). A maioria das instituições prisionais não dispõem de número adequado de servidores para que a movimentação ocorra sem que a rotina da escola seja afetada, o que implica em ausências e atrasos às aulas. Tais dificuldades têm sido apontadas ao longo dos anos em diversos estudos, incluindo os já citados neste artigo, e continuamos a viver "as agruras do descompasso entre o legal e o instituído na prática, tão comum na cultura política do nosso Estado" (JULIÃO, 2016, p. 33).

\subsection{Demanda e oferta da EJA - situação das mulheres}

Capturar a oferta e a demanda da EJA no conjunto dos planos analisados, com atenção específica à situação das mulheres, não foi uma tarefa fácil. Estudiosas 
de gênero, assumindo o papel central da linguagem nas representações de gênero, problematizam o modo como uma linguagem masculina atravessa as práticas sociais e os modos como são narradas, dificultando visibilidades de gênero e revelando uma sociedade que se organiza pela ótica do masculino (LOURO, 1997; MEYER et al., 2014; PARAÍSO; CALDEIRA, 2018; SCOTT, 1990).

Em que pese o fato de a maioria da população carcerária ser constituída por homens, muitas mulheres, e em números crescentes, como discutido na seção anterior, encontram-se hoje em situação de privação de liberdade. É esse número expressivo de mulheres que nos faz olhar com preocupação para um cenário de ocultamentos de gênero, que identificamos nos Planos Estaduais. Nossa expectativa era a de que os planos possibilitassem identificar, separadamente, os dados relativos à escolarização com o recorte de gênero, o que não foi possível. Os documentos, em geral, não apresentam separadamente as informações sobre demanda e atendimento educacional de homens e mulheres nas instituições prisionais mistas, e prevalece nesses documentos uma linguagem masculina, como se pode conferir nos excertos discursivos extraídos desses documentos, que informam o "número de presos matriculados"; "matrículas dos alunos"; "quantidade de presos matriculados"; "total de alunos matriculados".

Essa linguagem masculina é denunciada por Bonatto e Brandalise (2019) ao analisarem o Plano Estadual do Paraná, que, segundo as autoras, carece de "um posicionamento discursivo claro em relação à concepção e às questões de gênero que subsidiem a possibilidade de acesso à Educação no ambiente prisional de acordo com a diversidade e as especificidades de gênero" (p. 44).

O Relatório de Gestão produzido sob supervisão do Departamento de Monitoramento e Fiscalização do sistema carcerário e do sistema de execução de medidas socioeducativas chama a atenção para o fato de que

Historicamente, a ótica masculina tem sido tomada como regra para o contexto prisional, com prevalência de serviços e políticas penais direcionados para homens, deixando em segundo plano as diversidades que compreendem a realidade prisional feminina, que se relacionam com sua raça e etnia, idade, deficiência, orientação sexual, identidade de gênero, nacionalidade, situação de gestação e maternidade, entre tantas outras nuanças. Há grande deficiência de dados e indicadores sobre o perfil de mulheres em privação de liberdade nos bancos de dados oficiais governamentais, o que contribui para a invisibilidade das necessidades dessas pessoas (BRASIL, 2017a, p. 122). 
Buscando trazer a visibilidade da oferta de Educação escolar para as mulheres, empreendemos o exercício de buscar nos Planos Estaduais as referências às instituições prisionais exclusivamente femininas e destacar a relação entre demanda e atendimento da EJA. Foram identificadas 55 instituições prisionais unicamente femininas no conjunto dos planos, mas não nos foi possível localizar, para todas, a informação sobre demanda e/ou atendimento educacionais. Os dados que sintetizamos devem, pois, ser lidos considerando esses limites; optamos por apresentá-los, apesar de sua imprecisão, para não incidir mais uma vez no ocultamento das condições de vida das mulheres em privação de liberdade, que é, enfim, o encobrimento dessas pessoas (Tabela 2).

Tabela 2 - Demanda e atendimento escolar em estabelecimentos prisionais femininos (Alfabetização, EF e EM)

\begin{tabular}{|c|c|c|c|c|c|c|c|c|c|c|c|c|c|}
\hline \multicolumn{14}{|c|}{ DEMANDA E ATENDIMENTO ESCOLAR NOS ESTABELECIMENTOS PRISIONAIS FEMININOS } \\
\hline & \multicolumn{2}{|c|}{$\begin{array}{c}\text { Centro- } \\
\text { oeste }\end{array}$} & \multicolumn{2}{|c|}{ Norte } & \multicolumn{2}{|c|}{ Nordeste } & \multicolumn{2}{|c|}{ Sudeste } & \multicolumn{2}{|c|}{ Sul } & \multicolumn{2}{|c|}{ Brasil } & \multirow{2}{*}{$\begin{array}{c}\text { \% de } \\
\text { atendi- } \\
\text { mento } \\
\text { em } \\
\text { relação a } \\
\text { demanda } \\
\text { (Brasil) }\end{array}$} \\
\hline $\begin{array}{l}\text { Nível } \\
\text { escolar }\end{array}$ & 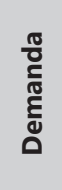 & 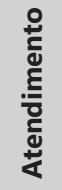 & $\begin{array}{l}\frac{\pi}{0} \\
\frac{0}{\pi} \\
\text { है } \\
\text { อั }\end{array}$ & 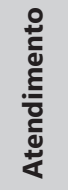 & $\begin{array}{l}\frac{\pi}{0} \\
\frac{0}{\pi} \\
\frac{8}{0} \\
0\end{array}$ & 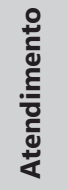 & $\begin{array}{l}\frac{\pi}{0} \\
\frac{0}{\pi} \\
\frac{\pi}{0} \\
\text { है }\end{array}$ & 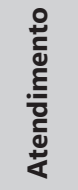 & 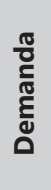 & 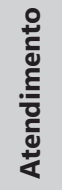 & $\begin{array}{l}\frac{\pi}{0} \\
\frac{0}{0} \\
\text { है } \\
\text { อ }\end{array}$ & 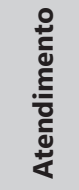 & \\
\hline $\begin{array}{l}\text { Alfabe- } \\
\text { tização }\end{array}$ & 9 & 0 & 394 & 124 & 47 & 67 & 561 & 18 & 0 & 34 & 1011 & 243 & $24,00 \%$ \\
\hline $\begin{array}{l}\text { Ensino } \\
\text { Funda- } \\
\text { mental }\end{array}$ & 522 & 310 & 3044 & 498 & 285 & 502 & 4794 & 1739 & 0 & 144 & 8645 & 3193 & $37,00 \%$ \\
\hline $\begin{array}{l}\text { Ensino } \\
\text { Médio }\end{array}$ & 218 & 40 & 1293 & 106 & 58 & 84 & 3574 & 823 & 0 & 53 & 5143 & 1106 & $22,00 \%$ \\
\hline
\end{tabular}

Fonte: Elaboração própria (2018) a partir de Planos Estaduais

Os dados relativos à oferta da EJA nessas 55 instituições prisionais evidenciam um atendimento a $24 \%$ das mulheres que demandam processos de alfabetização; $37 \%$ das que não completaram o EF e $22 \%$ das que poderiam cursar o EM.

Os dados do Infopen-Mulheres, publicado no ano de 2014, portanto, no movimento de elaboração dos Planos Estaduais, mostram que 50\% das mulheres aprisionadas no País não concluíram o EF, e somente 11\% delas concluíram o EM (BRASIL, 2014). A demanda pela escola na prisão para essas mulheres persiste nos dados do relatório publicado em 2017: 45\% das mulheres não concluíram o EF e apenas 15\% concluíram o EM (BRASIL, 2018). 
Dados comparativos sobre a escolaridade de mulheres e de homens apontam um nível de escolaridade ligeiramente maior das mulheres: " $4 \%$ das mulheres encarceradas são analfabetas, contra 5\% dos homens; $11 \%$ das mulheres encarceradas concluíram o EM, contra 7\% dos homens encarcerados" (BRASIL, 2014, p. 26) ${ }^{6}$. Verifica-se, ainda, certa vantagem das mulheres em prisões exclusivamente femininas, com relação à possibilidade de aumento da escolaridade. No caso dos estabelecimentos mistos, porém, essa vantagem fica comprometida. Nessas estruturas, as mulheres são minoria e os estabelecimentos, por abrigarem uma maioria masculina, priorizam o atendimento aos homens. Há que se considerar, em relação à ocupação dos estabelecimentos prisionais por gênero, os dados relativos ao ano de 2017, e a denúncia apresentada no relatório, destacando

[...] que grande parte dos estabelecimentos penais foram construídos para custodiar o público masculino. De todas as unidades cadastradas no Infopen, 74,8\% dessas destinam-se aos homens, $6,9 \%$ às mulheres e outros $18,1 \%$ são destinadas a ambos os públicos, havendo alas/celas destinadas para o aprisionamento de mulheres (MOURA, 2019, p. 20).

Se retornamos aos Planos analisados, podemos afirmar que eles, ao não contabilizarem nos estabelecimentos mistos as diferenças de acesso à escolaridade de mulheres e homens, contribuem para silenciamentos e desigualdades de gênero, que se somam a outras dificuldades vividas pelas mulheres, como o acesso à saúde, a restrição a visitas íntimas, o espaço adequado para aleitamento materno, o espaço para receber visita de filhos (as), por exemplo. Com efeito, na lógica da organização prisional, predomina uma universalidade masculina que

tem precedência em relação à prisão feminina, que é considerada uma exceção. A peculiaridade do perfil da mulher criminosa reforça, inclusive, a escala de classificação dos presídios entre mais perigoso e menos perigoso. Assim, ao se organizarem aos modos masculinos, os presídios, de certa forma, também reforçam a tentativa de produção da inexistência, ao impor-se à mulher apenada a lógica dessa predominância (NONATO, 2011, p. 136).

O Infopen publicado em 2019 não apresentava comparativos relacionados à escolaridade de mulheres e homens (MOURA, 2019). 


\section{Outros olhares}

A reflexão sobre o acesso à escola na prisão que a análise dos planos nos possibilita mobiliza-nos, entretanto, a prestar atenção às mulheres que adentram as salas de aula nesse espaço. Por isso, na tentativa de ampliar o debate sobre a Educação escolar de mulheres em situação de privação de liberdade, lançamos outros olhares sobre elas, balizando-nos na reflexão e na empiria de artigos publicados no período de 2008 a 2018, reunidos por meio de um levantamento sistemático, usando termos de busca Gênero e Sistema Prisional, no Portal de Periódicos da Coordenação de Aperfeiçoamento de Pessoal de Nível Superior (Capes), além de outros estudos a que tivemos acesso ao longo de nossas atividades de pesquisa sobre essa temática. As contribuições desses artigos foram confrontadas com informações apresentadas em documentos públicos relativos à situação de mulheres aprisionadas, para que pudéssemos encontrar referências à vida dessas mulheres, que não são "dotadas de nenhuma dessas grandezas estabelecidas e reconhecidas - as do nascimento, da fortuna, da santidade, do heroísmo ou do gênio; que pertencem a essas milhares de existências destinadas a passar sem deixar rastro" (FOUCAULT, 2006, p. 207), e que carregam as marcas das desigualdades de gênero historicamente constituídas.

Diferentes documentos, delineiam o perfil das mulheres aprisionadas: em sua maioria, são jovens, afrodescendentes, com baixa escolaridade, mães solteiras, em geral, únicas responsáveis pela criação de filhos (as), grande parte condenada por envolvimento com o tráfico de drogas (BRASIL, 2014; CARREIRA, 2009). No Infopen-Mulheres, divulgado em 2018, confirma-se esse perfil: jovens entre 18 a 29 anos representam $50 \%$ da população prisional feminina; mulheres negras representam $62 \%$ dessa população; somente $15 \%$ das mulheres privadas de liberdade concluíram o EM; $62 \%$ das mulheres são solteiras. Com relação ao número de filhos, o documento salienta que só foi possível identificar os dados relativos a $7 \%$ dessa população, e nessa amostra, $74 \%$ das mulheres têm filhos (BRASIL, 2018).

Sobre a situação das mulheres no sistema prisional, cumpre destacar a importância das "Regras das Nações Unidas para o tratamento de mulheres presas e medidas não privativas de liberdade para mulheres infratoras (Regras de Bangkok)", de 2009 (BRASIL, 2016). Reconhecendo a necessidade de atenção especial ao aumento de mulheres presas em todo o mundo e às desigualdades de gênero que alcançam as prisões, essas regras, embora não tratem de modo específico o direito à Educação, fazem-se relevantes nesse debate, por explicitar questões como saúde, gestação, maternidade, violência contra a mulher, visitas íntimas, prevenção contra práticas 
e normas sociais discriminatórias, dentre outros aspectos, na busca pela equidade de gênero, que se faz premente no contexto do encarceramento.

A necessidade do estabelecimento de tais regras reflete o acirramento das desigualdades de gênero nos espaços prisionais, que, além de disciplinadores e normalizadores, como tão bem os retrata Foucault (2006), são, ademais, organizados sob a ótica do masculino, penalizando-se, desse modo, duplamente as mulheres privadas de liberdade, como se pode conferir nas preocupações expressas nas Regras de Bangkok.

Pode-se captar no material que reunimos, especialmente nos textos que se dedicaram a um olhar mais atento sobre a Educação de mulheres na prisão, as tramas nas quais singularidades e desigualdades de gênero se entrelaçam, adentrando as salas de aula. São essas tramas que queremos destacar nesta reflexão.

Uma primeira trama relaciona-se ao direito à Educação. As mulheres que estudam nas prisões narram histórias similares das impossibilidades de estudo anterior ao encarceramento: falta ou distância das escolas nos lugares em que viviam, quando crianças e adolescentes; necessidade de ajudar a mãe, em casa, no cuidado com irmãos menores, ou no trabalho fora de casa para contribuir no orçamento doméstico, especialmente na ausência de um pai; trabalho, quando ainda em idade escolar, muitas vezes em casas de famílias que não as encaminhavam à escola; cerceamentos de gênero ("mulher não precisa estudar"), feitos por pais e companheiros; gravidez precoce, trazendo a necessidade de interrupção dos estudos (CUNHA, 2010; GRACIANO, 2010; GRACIANO; SCHILLING, 2008; NONATO, 2011; SANTOS; DURANT, 2014; SOUZA; NONATO; BICALHO, 2017).

Uma segunda trama, identificada nos textos analisados, é a marca da maternidade, que produz, tanto restrições, quanto mobilização na escola dos presídios. As preocupações com os (as) filhos (as) adentram os espaços da prisão e assumem contornos dramáticos, já que elas não podem acompanhar o cotidiano de sua prole. Há preocupações com a subsistência, pois muitas "são as responsáveis pela provisão do sustento familiar" (BRASIL, 2014, p. 5), com os cuidados diários; com a dificuldade em acompanhar o crescimento, especialmente, na adolescência, com as filhas deixadas sob o cuidado de outros; com o envolvimento com o que consideram "caminho errado", "más companhias"; e com os processos escolares, como elas mesmas relatam: "Meu menino abandonou a escola, largou, mas eu, saindo agora, vou ver se eu converso com ele, ele tem 17 anos"; " a minha filha agora tem 14 anos e também não quer ir pra escola"(SOUZA; BICALHO; NONATO, 2013, p. 17). 
De modo geral, elas preocupam-se com o "destino dos filhos" (GRACIANO, 2010, p. 53). Essas preocupações provocam ausências às aulas e adoecimentos, e são evocadas para justificar dificuldades e desatenções na escola por não "ter cabeça para estudar" (GRACIANO; SHCILLING, 2008, p. 127).

Por sua vez, a maternidade também as mobiliza em direção à escola. Estudar significa possibilidade de dominar a escrita para se comunicar com os (as) filhos (as), por meio de cartas, de conquistar o respeito deles (as), dar exemplo, dar uma vida melhor para eles (as) ao sair da prisão, e mostrar que, mesmo na condição de aprisionamento, ocuparam-se de algo valorizado pela sociedade, "o estudo" (GRACIANO, 2010; GRACIANO; SHCILLING, 2008; IRELAND; LUCENA, 2013; NONATO, 2011; SOUZA; BICALHO; NONATO, 2013). Nesse sentido, a escola na prisão se lhes apresenta como oportunidade: "porque lá fora não tem jeito, é difícil, trabalhar, cuidar dos filhos"; "porque [fora da prisão] a primeira coisa que eu ia pensar ia ser nas minhas filhas, não deixar faltar nada pra elas" (SOUZA; NONATO; BICALHO, 2017, p. 12).

Outra trama diz respeito aos cerceamentos próprios da prisão, e como eles provocam um movimento tenso entre a humanização, contemplada nos processos educativos, e o disciplinamento que se liga ao processo de aprisionamento, conforme pontuam diversos estudos aqui citados.

No caso específico das mulheres, a atenção à situação e às condições do aprisionamento feminino foi ponto de pauta de diferentes debates e de registros documentais. De acordo com Carreira (2009), relatório elaborado em 2007, por diferentes organizações em prol dos direitos humanos e pela equidade de gênero, colocava em pauta as condições carcerárias: cadeias públicas e delegacias de polícia sendo utilizadas para cumprimento de pena; violações de gênero expressas nas inadequações arquitetônicas e condições de saneamento básico; escassez de produtos de higiene, incluindo absorventes íntimos e carências diversas no campo da saúde; falta de condições de amamentação; violência sexual e/ou tortura psicológica.

Em muitas unidades, a violação de direitos, vivida pela gigantesca maioria da população prisional, tem sua perversidade acentuada no caso das mulheres. A elas, são negadas unidades com quadra de esporte, atendimento de saúde especializado, convivência com os filhos pequenos, visitas íntimas, acesso a determinados livros e Educação profissional, que vá além dos cursos e oficinas de pequena duração, considerados tradicionalmente 'de mulheres'. O reforço aos estereótipos de gênero está na origem das prisões femininas no 
Brasil, que nasceram vinculadas a ordens religiosas como espaços de 'purificação' das 'mulheres criminosas' (CARREIRA, 2009, p. 23, aspas do texto).

A situação e as condições do aprisionamento, aliadas às normas disciplinares da prisão, muitas vezes, inviabilizam o acesso à escola (mesmo quando a oferta apresenta-se), adentram as salas de aula e interferem nos processos educativos, como as pesquisas têm demonstrado. Os estudos já citados narram os cerceamentos próprios da prisão (vigilâncias e sanções), os trâmites processuais que interferem no acesso e na continuidade de estudos, a suspensão temporária da frequência à escola como medida punitiva, a incompatibilidade de horários de trabalho e escola, a tensa relação entre a opção pelo trabalho e a opção pelo estudo, a restrição ao acesso à Educação com base no lugar de reclusão, duração da pena e/ou a categoria de segurança.

Por sua vez, esses estudos evidenciam o quanto a escola significa para essas mulheres. O retorno aos estudos, na prisão, coloca-se, para muitas delas, como a realização de um sonho, a conquista de um direito negado. Podendo frequentar a escola na prisão, "ainda que de forma parcial e sem a qualidade socialmente reconhecida, [elas] tendem a perceber a Educação como meio de acessar esse e outros direitos, e mais, reconhecer sua própria condição humana" (GRACIANO; SCHILLING, 2008, p. 127).

Pode-se apontar, ainda, como significados por elas atribuídos à escola na prisão: a oportunidade de cuidado consigo mesmas, quando se tem mais tempo para si, mesmo que em um espaço adverso; o novo sentido que elas atribuem às aprendizagens escolares, às quais, de certo modo, muitas tiveram acesso em trajetórias escolares interrompidas; a valorização dessas aprendizagens, inclusive para compreender a situação da pena, e entender algo da linguagem jurídica; outras aprendizagens ligadas à convivência, como espaço de afetos, construídos especialmente na relação com docentes; reconhecimento familiar e investimento em projetos futuros (GRACIANO, 2010; GRACIANO; SCHILLING, 2008; IRELAND; LUCENA, 2013; NONATO, 2011; SANTOS; DURANT, 2014; SOUZA; BICALHO; NONATO, 2013; SOUZA; NONATO; BICALHO, 2017).

Em relação a esses projetos, a saída da prisão é, para elas, o horizonte a ser alcançado, e, nesse sentido, a possibilidade de remição da pena, pelo estudo, também as mobiliza para a escola: "a remição na escola conta muito"; porque "na escola cai um sexto da minha pena" (SOUZA; NONATO; BICALHO, 2017). 
No entanto, não sendo o acesso à Educação garantido igualmente a todas as mulheres e a todos os homens, em situação de aprisionamento, a remição pelo estudo incidirá desigualmente na situação e nas condições de confinamento e nos projetos de vida das mulheres presas.

\section{Conclusão}

No sistema prisional, sob o qual pesam o estigma, a vulnerabilidade e que, visivelmente, reflete as desigualdades sociais, a Educação busca firmar-se como um direito. Houve avanços legais na última década, dentre os quais, destacamos a articulação entre o Ministério da Justiça e o Ministério da Educação, traduzida na elaboração dos Planos Estaduais. A leitura desses Planos, entretanto, revela a insuficiência e a precariedade do atendimento educacional da população encarcerada e nos leva a defender a oferta de Educação escolar e de atividades complementares de cultura, esporte, inclusão digital, Educação profissional, fomento à leitura e programas de implantação, recuperação e manutenção de bibliotecas.

Assim, em que pese o cenário da Educação prisional no Brasil indicar avanços, a leitura dos Planos mostra ainda um longo caminho a percorrer para que o direito à Educação seja efetivado: no aumento da oferta de vagas em todos os níveis; nas questões físicas e estruturais (salas de aula, bibliotecas, salas de informática, quadras etc.); no quadro de pessoal, que precisa ser recomposto, tendo em vista as demandas específicas das atividades educativas; na adequação do projeto pedagógico e na elaboração de um currículo que acolha as demandas do contexto do aprisionamento e que, ao mesmo tempo, contribua para a reinserção dos sujeitos na vida social pós-situação do aprisionamento.

Nesse cenário, torna-se preocupante a Resolução $\mathrm{n}^{\circ} 06$, que dispõe sobre a flexibilização das Diretrizes Básicas para Arquitetura Penal (BRASIL, 2017b). Ao contrário das diretrizes anteriores (BRASIL, 2011c), as quais continham a previsão de módulo de ensino, como "espaço destinado às atividades de ensino formal, informal e profissionalizante e atividades da comunidade com as pessoas presas" (BRASIL, 2011c, p. 66), as novas diretrizes não contemplam espaços educativos. A não obrigatoriedade da construção desses espaços compromete, visivelmente, a garantia do direito à Educação de homens e de mulheres em situação de aprisionamento, e aponta para um cenário que acirra as desigualdades educacionais no campo da EJA e demarca retrocesso em termos da garantia do direito à Educação.

As precariedades que afligem toda a população das prisões são, entretanto, agravadas pelas tramas que entrelaçam singularidades e desigualdades de 
gênero, e que se refletem na escassez de oportunidades educativas para mulheres presas, ou nos modos restritivos como tais oportunidades efetivam-se. Ao refletirmos, neste texto, sobre a Educação dessas mulheres, ressaltamos a necessidade de se pensar em um processo que as torne visíveis, a despeito do local do aprisionamento (instituições mistas, ou não), e que considere as tramas nas quais as desigualdades de gênero se entrelaçam e que as acompanham na situação e nas condições do aprisionamento. 


\title{
Scenarios of Education of young and adult women in a situation of deprivation of liberty in the Brazilian context
}

\begin{abstract}
In this paper, we discuss the offer of school Education for imprisoned women, seeking to identify, in this offer, reflections of the singularities of the female condition and historically constituted gender inequalities. The State Prison Education Plans of the 26 Brazilian states, available on the website of the Penitentiary Department of the Ministry of Justice and Public Security, were analyzed. The analysis of the data brought by that such plans dialogue with reflections and empirical material from other studies on Education and gender in the Brazilian prison system. Results indicate advances in the legal field, but point out a long way to go to guaranteeing the right to school Education in prison, especially for women: in the different places and types of imprisonment, it is necessary to develop Educational processes that do not make women invisible and consider the plots in which gender inequalities intertwine.
\end{abstract}

Keywords: Gender. Education. Prison system.

\section{Escenarios de la Educación de mujeres jóvenes y adultas em situación de privación de libertad en el contexto brasileño}

\section{Resumen}

En este artículo, discutimos la oferta de Educación escolar para mujeres encarceladas, tratando de identificar, en esta oferta, reflexiones de las singularidades de la condición femenina y de las desigualdades de género históricamente constituidas. El corpus documental analizado está compuesto por los Planes Estatales de Educación Penitenciaria de los 26 estados brasileños, disponibles en el sitio web del Departamento Penitenciario del Ministerio de Justicia y Seguridad Pública. El análisis de los datos aportados por dichos planes dialoga con reflexiones y material empírico de otros estudios sobre Educación y género en el sistema penitenciario brasileño. Los resultados indican avances en el campo legal, pero señalan un largo camino por recorrer para garantizar el derecho a la Educación escolar en prisión, especialmente para las mujeres: en los diferentes lugares y tipos de encarcelamiento, es necesario desarrollar procesos educativos que las hagan visibles y considerar las tramas en las que se entrelazan las desigualdades de género.

Palabras clave: Género. Educación. Sistema penitenciario. 


\section{Referências}

BONATTO, B. M.; BRANDALISE, M. A. T. Avaliação do plano estadual de Educação no sistema prisional do Paraná: questões de gênero no campo acadêmico da Educação prisional. Imagens da Educação, Maringá, v. 9, n. 1, p. 43-58, maio 2019. https://doi.org/10.4025/imagenseduc.v9i1.44262

BRASIL Constituição da República Federativa do Brasil. Brasília, DF. Senado Federal, 1988.

BRASIL. Decreto $n^{0} 7.626$, de 24 de novembro de 2011a. Institui o Plano Estratégico de Educação no âmbito do Sistema Prisional. Diário Oficial da União, Brasília, DF, 25 nov. 2011.

BRASIL. Lei n ${ }^{\circ} 7.210$, de 11 de julho de 1984. Institui a Lei de Execução Penal. Diário Oficial da União, Brasília, DF, 13 jul. 1984.

BRASIL. Lei no 9.394, de 20 de dezembro de 1996. Estabelece diretrizes e bases da Educação nacional. Diário Oficial da União, Brasília, DF, 23 dez. 1996.

BRASIL. Lei $n^{\circ} 12.433$, de 29 de junho de 2011b. Altera a Lei $n^{0} 7.210$, de 11 de julho de 1984 (Lei de Execução Penal), para dispor sobre a remição de parte do tempo de execução da pena por estudo ou por trabalho. Diário Oficial da União, Brasília, DF, 30 jun. 2011.

BRASIL. Regras das Nações Unidas para o tratamento de mulheres presas e medidas não privativas de liberdade para mulheres infratoras (Regras de Bangkok). Brasília, DF, 2016. Disponível em: https:/www.cnj.jus.br/wp-content/ uploads/2019/09/cd8bc11ffdcbc397c32eecdc40afbb74.pdf. Acesso em: 10 dez. 2017.

BRASIL. Relatório de Gestão - Supervisão do Departamento de Monitoramento e Fiscalização do sistema carcerário e do sistema de execução de medidas socioeducativas - DMF. Brasília, DF, 2017a. Disponível em: https://www.cnj.jus.br/wp-content/uploads/2018/10/23902dd211995b2bcb a8d4c3864c82e2.pdf. Acesso em: 10 dez. 2017.

BRASIL. Resolução CNE/CEB nº 2, de 19 de maio de 2010. Dispõe sobre as Diretrizes Nacionais para a oferta da Educação para jovens e adultos em situação de privação de liberdade nos estabelecimentos penais. Diário Oficial da União, Brasília, DF, 20 maio 2010.

BRASIL. Conselho Nacional de Política Criminal e Penitenciária. Diretrizes básicas para arquitetura prisional. Brasília, DF, 2011c. 
BRASIL. Ministério da Justiça. Levantamento Nacional de Informações Penitenciárias - Infopen mulheres 2000-2014. Brasília, DF, 2014.

BRASIL. Ministério da Justiça e Segurança Pública. Levantamento Nacional de Informações Penitenciárias - Infopen Mulheres. Brasília, DF, 2018.

BRASIL. Ministério da Justiça e Segurança Pública. Resolução nº 6, de 7 de dezembro de 2017b. Dispõe sobre a flexibilização das Diretrizes Básicas para Arquitetura Penal. Diário Oficial da União, Brasília, DF, 13 dez. 2017.

CARRREIRA, D. Relatoria Nacional para o Direito Humano à Educação: Educação nas Prisões Brasileiras. São Paulo: Plataforma DhESCA, 2009. Disponível em: http://www.plataformadh.org.br/. Acesso em: 8 nov. 2017.

CORCETTI, E., SOUZA, S. P., LORETO, M. D. S. O "Programa Mulheres Mil" no Espírito Santo: uma política pública educacional de equidade de gênero? Ensaio: Avaliação e Políticas Públicas em Educação, Rio de Janeiro, v. 26, n.100, p. 911-943, jul. 2018. http://dx.doi.org/10.1590/s0104-40362018002601027

CUNHA, E. L. Ressocialização: o desafio da Educação no sistema prisional feminino. Cadernos Cedes, Campinas, v. 30, n. 81, p. 157-178, maio/ago. 2010. https://doi.org/10.1590/S0101-32622010000200003

FOUCAULT, M. Estratégia, poder-saber. Rio de Janeiro: Forense Universitária, 2006.

GRACIANO, M. Para início de conversa: as mulheres e a Educação nas prisões. In: YAMAMOTO, A. Cereja discute: educação em prisões. São Paulo: Alfasol, 2010. p. 59-61.

GRACIANO, M.; SCHILLING, F. A Educação na prisão: hesitações, limites e possibilidades. Estudos de Sociologia, Araraquara, v. 13, n. 25, p. 111-132, 2008. Disponível em: https://periodicos.fclar.unesp.br/estudos/article/view/1148/934. Acesso em: 15 jan. 2017.

IRELAND, T. D. (org.). Educação em prisões. Em Aberto, Brasília, DF, v. 24, n. 86, p.1-179, nov. 2011. https://doi.org/10.24109/2176-6673.emaberto.24i86

IRELAND, T. D.; LUCENA, H. H. R. O presídio feminino como espaço de aprendizagens. Educação \& Realidade, Porto Alegre, v. 38, n. 1, p. 113-136, jan./mar. 2013. https://doi.org/10.1590/S2175-62362013000100008

JULIÃO, E. F. Educação para jovens e adultos em situação de restrição e privação de liberdade: questões, avanços e perspectivas. Jundiaí: Paco, 2013. 
JULIÃO, E. F. Escola na ou da prisão? Cadernos

Cedes, Campinas, v. 36, n. 98, p. 25-42, jan./abr. 2016.

https://doi.org/10.1590/CC0101-32622016162554

LOURO, G. L. Gênero, sexualidade e educação: uma perspectiva pósestruturalista. Petrópolis: Vozes, 1997.

MEYER, D. E. et al. Políticas públicas: imperativos e promessas de inclusão social. Ensaio: Avaliação e Políticas Públicas em Educação, Rio de Janeiro, v. 22, n. 85, p. 1001-1026, out. 2014. https://doi.org/10.1590/S0104-40362014000400007

MOURA, M. V. (org.). Levantamento nacional de informações penitenciárias, atualização junho de 2017. Brasília, DF: Ministério da Justiça e Segurança Pública, 2019.

NONATO, E. M. N. Educação de mulheres em situação de privação de liberdade. Em aberto, Brasília, DF, v. 24, n. 86, p. 127-140, 2011. https://doi.org/10.24109/2176-6673.emaberto.24i86.2319

ONOFRE, E. M. C.; JULIÃO, E. F. A Educação na prisão como política pública: entre desafios e tarefas. Educação \& Realidade, Porto Alegre, v. 38, n. 1, p. 51-69, jan./mar. 2013. https://doi.org/10.1590/S2175-62362013000100005

ORGANIZAÇÃO DAS NAÇÕES UNIDAS - ONU. Declaração Universal dos Direitos Humanos. Disponível em: https://nacoesunidas.org/wp-content/uploads/2018/10/DUDH.pdf/. Acesso em: 15 jan. 2020.

PARAÍSO, M. A.; CALDEIRA, M. C. S. (orgs.). Pesquisas sobre currículos, gêneros e sexualidades. Belo Horizonte: Mazza, 2018.

SANTOS, P.; DURANT, O. C. S. A Educação de jovens e adultos no Espaço Prisional: sentidos da escolarização para mulheres em privação de liberdade. Perspectiva, Florianópolis, v. 32, n. 1, 129-159, jan./abr. 2014. https://doi.org/10.5007/2175-795X.2014v32n1p129

SCOTT, J. Gênero: uma categoria útil de análise histórica. Educação e Realidade, Porto Alegre,v. 20, n. 2, p. 5-22, 1990. Disponível em: https://seer.ufrgs.br/educacaoerealidade/article/view/71721/40667. Acesso em: 20 ago. 2017. 
SOUZA, M. C. R. F; BICALHO, M. G. P.; NONATO, E. M. N. Trajetórias e vivências escolares de mulheres em situação de privação de liberdade. Arquivos Analíticos de Políticas Educativas, v. 21, n. 76, p. 2-19, set. 2013. https://doi.org/10.14507/epaa.v21n76.2013

SOUZA, M. C. R. F; NONATO, E. M. N; BICALHO, M. G. P. Lógicas de exclusão/inclusão dos processos educativos no contexto prisional feminino. Educação \& Sociedade, Campinas, v. 38, n. 138, p. 45-62, jan./mar. 2017. https://doi.org/10.1590/es0101-73302016158634

\section{Informações das autoras}

Maria Celeste Reis Fernandes de Souza: Doutora em Educação pela Universidade Federal de Minas Gerais. Pesquisadora e docente do Programa de Pós-graduação em Gestão Integrada do Território da Universidade Vale do Rio Doce. Contato: celeste.br@gmail.com (iD) http://orcid.org/0000-0001-6955-5854

Eunice Maria Nazareth Nonato: Doutora em Ciências Sociais pela Universidade do Vale do Rio dos Sinos. Pesquisadora e docente do Programa de Pós-graduação em Gestão Integrada do Território da Universidade Vale do Rio Doce. Contato: eunicenazarethe@hotmail.com (iD) http://orcid.org/0000-0003-3583-3777

Maria da Conceição Ferreira Reis Fonseca: Doutora em Educação pela Universidade Estadual de Campinas. Pesquisadora e Docente do Programa de Pós-graduação em Educação: Conhecimento e Inclusão Social da Universidade Federal de Minas Gerais. Contato:mcfrfon@gmail.com

(iD) https://orcid.org/0000-0002-5702-7189 